\title{
Light and Dark Cause a Shift in the Spatial Expression of a Neuropeptide-Processing Enzyme in the Rat Retina
}

\author{
Cassandra L. Schlamp ${ }^{1}$ and Robert W. Nickells ${ }^{1,2}$ \\ Departments of ${ }^{1}$ Ophthalmology and Visual Sciences, and ${ }^{2}$ Neurophysiology, University of Wisconsin, \\ Madison, Wisconsin 53792
}

\begin{abstract}
Carboxypeptidase E (CPE, EC 3.4.17.10) is an essential enzyme in the post-translational processing of most neuroactive peptides. We have studied how the expression of CPE in the rat retina is modified in response to the light/dark cycle. Retinal CPE mRNA levels increase immediately after a change in lighting condition. After prolonged exposure to the dark or the light, however, CPE mRNA levels drop to comparable amounts. The increase CPE mRNA is most dramatic during the dark-to-light transition. Interestingly, during the same interval, CPE protein levels transiently decrease. This apparently contradictory change in mRNA and protein levels is attributable to a change in the spatial pattern of CPE expression in the retina in response to light and dark. Both in situ hybridization and indirect
\end{abstract}

immunofluorescence studies indicate that CPE is expressed in photoreceptors in the dark. During light onset, CPE expression is rapidly induced in retinal ganglion cells, whereas expression in photoreceptors is reduced. This pattern is reversed when the animals are exposed to the dark. in contrast, CPE is apparently constitutively expressed in a subpopulation of cells in the inner nuclear layer in both the light and the dark. These changes in CPE expression are similar to light-induced changes in c-fos expression, suggesting that CPE may be a downstream target for Fos activation.

Key words: carboxypeptidase E; neuropeptides; retina; photoreceptors; ganglion cells; enkephalin; c-fos
Many animals have developed a circadian rhythm that is regulated by a repeating cycle of light and dark. These animals exhibit changes in behavior and biochemical activity to prepare for expected changes in the light. The vertebrate retina, for example, exhibits alterations in retinal gene expression, which have been most well documented in photoreceptor cells. In general, gene products involved in the phototransduction cascade, such as opsin and the S-antigen, begin to accumulate in photoreceptors just before a predicted time of light-onset. This accumulation continues until some time before a predicted time of dark-onset (Bowes et al., 1988; Korenbrot and Fernald, 1989; Craft et al., 1990; McGinnis et al., 1992). The activation of synthesis is not dependent exclusively on the circadian clock, however, because similar changes can be stimulated in dark-adapted retinae that receive light stimuli before the expected time (Craft et al., 1990).

I ight-induced changes in gene expression are likely mediated primarily at the level of transcription because increased mRNA accumulation always precedes elevated protein levels (Korenbrot and Fernald, 1989; Craft et al., 1990). This has led to the speculation that light also stimulates the transcription of primary control genes, which are likely to encode both positive and negative transcription factors. Yoshida et al. (1993) and Nir and Agarwal

\footnotetext{
Received Oct. 30, 1995; revised Dec. 21, 1995; accepted Jan. 5, 1996.

This work was supported in part by a Career Development Award to R.W.N. and an unrestricted gift to the Department of Ophthalmology and Visual Sciences by the Research to Prevent Blindness, Inc., and by a Grant-in-Aid from Fight-for-Sight, The Research Division of Prevent Blindness America to R.W.N. We thank Dr. I loyd Fricker for the generous gift of antisera directed at either the $\mathrm{N}$ terminus or the $\mathrm{C}$ terminus of mature CPE and their corresponding peptides, and we thank the Comprehensive Cancer Center at the University of Wisconsin for the use of the facility's PhosphorImager.

Correspondence should be addressed to Dr. Robert W. Nickells, Department of Ophthalmology and Visual Sciences, K6/458 CSC, University of Wisconsin, 600 Highland Avenuc, Madison, WI 53792.

Copyright (c) 1996 Society for Neuroscience 0270-6474/96/162164-08\$05.00/0
}

(1993) described diurnal changes in the accumulation of c-fos mRNA in the mammalian retina, suggesting that this transcription factor may be one of the primary regulators of light-dependent gene expression in this tissue. Interestingly, the spatial distribution of c-fos mRNA changes during the transitions between dark and light (Yoshida et al., 1993). In situ hybridization studies show that c-fos mRNA accumulates only in photoreceptor cells in the dark, whereas in the light it accumulates only in the cells of the inner nuclear and ganglion cell layers.

Retinal genes that may be positively regulated by c-fos include those involved in the synthesis and processing of neuropeptides (Sonnenberg et al., 1989). Several neuropeptides have been identified in the vertebrate retina, particularly in amacrine cells (Watt and Florack, 1991, 1994; Watt et al., 1991; Boelen et al., 1994). In most cases, these neuropeptides likely act as neurotransmitters. Opiates such as enkephalin, however, have been proposed to have other roles in the retina including modulating neuronal growth during development (Isayama et al., 1991) and regulating intraocular pressure (Rohde et al., 1993a). Most neuropeptides are derived from the proteolytic processing of larger polypeptides. These larger polypeptides are cleaved by a trypsin-like endopeptidase to release smaller fragments containing cryptic neuropeptides, which are processed further by the enzyme carboxypeptidase E (CPE, EC 3.4.17.10) to remove basic amino acids from their C termini (Fricker, 1988). CPE has also been called carboxypeptidase $\mathrm{H}$ (Rodriguez et al., 1989) and enkephalin convertase (Fricker and Snyder, 1982). Proteolytic processed peptides may then be modified by C-terminal amidation (Eipper and Mains, 1988) as a last step in their maturation. In the retina, the generation of mature neuropeptides is regulated by the light/dark cycle. Previously, we characterized the expression of CPE in the retinae of Long-Evans rats, particularly with respect to expression in photoreceptor cells (Nickells et al., 1993). In the present report, 
we demonstrate that $\mathrm{CPE}$ expression in the retina is regulated by the light/dark cycle, in which the spatial pattern of expression of $\mathrm{CPE}$ is altered, following a pattern nearly identical to that reported for c-fos.

\section{MATERIALS AND METHODS}

Experimental animals. The animals used in this study were handled in accordance with the Association for Research in Vision and Ophthalmology Resolution for the use of animals in research. Long-Evans rats were kept on a $12 \mathrm{hr}$ light/dark cycle (lights were switched on at $8 \mathrm{~A} . \mathrm{M}$. and switched off at 8 P.M.) for at least 3 weeks before use. At appropriate times during the light/dark cycle, rats were killed by decapitation or cervical dislocation immediately before removal of the globes. For biochemical analysis, the retinae were dissected from the eyes and snapfrozen in liquid nitrogen. These samples were then stored at $-80^{\circ} \mathrm{C}$ until use. For in situ hybridization and indirect immunofluorescent analysis, an incision was made at the midline of enucleated globes, which were then immersed in primary fix $(2 \%$ paraformaldehyde in $100 \mathrm{~mm}$ phosphate buffer, $\mathrm{pH}$ 7.2) for $1 \mathrm{hr}$ at room temperature. The globes were then transferred to secondary fix $(0.4 \%$ paraformaldehyde in phosphate buffer) and stored at $4^{\circ} \mathrm{C}$. The killing and processing of samples from dark-adapted animals was carried out under illumination from Kodak safe lamps containing number $1 \mathrm{~A}$ red filters.

Northern blot and RNase protection analysis. Total RNA was extracted from retinae using a one-step isolation procedure. Briefly, one to two frozen retinae were resuspended in $1 \mathrm{ml}$ of extraction buffer ( 1 part lysis buffer containing $4 \mathrm{~m}$ guanidine thiocyanate, $25 \mathrm{~mm}$ sodium citrate, $\mathrm{pH}$ 7.0, $100 \mathrm{~mm}$ 2-mercaptoethanol, $0.5 \%$ sarcosine; 1 part water-saturated phenol; and 0.2 part $200 \mathrm{~mm}$ sodium acetate, $\mathrm{pH} \mathrm{2.0)}$ and sonicated. Chloroform $(100 \mu \mathrm{l})$ was added to this homogenate, which was then vortexed and incubated on ice for $10 \mathrm{~min}$. The samples were then centrifuged at $4^{\circ} \mathrm{C}$ for $10 \mathrm{~min}$ in a microfuge, and the aqueous phase was removed and reextracted with an equal volume of chloroform. RNA was precipitated by the addition of an equal volume of 2-propanol followed by centrifugation for $30 \mathrm{~min}$ at $4^{\circ} \mathrm{C}$. Northern blot analysis was carried out using standard procedures described previously (Nickells et al., 1993). The CPE probe used in this study is a cDNA that encodes the final 132 nucleotides of rat retinal CPE mRNA (clone p21-8; Nickells et al., 1993). The extent of radioactivity hybridized to CPE mRNA was quantified directly from filters using a PhosphorImager (Molecular Dynamics, Sunnyvale, CA). Transcript abundance for each sample was then normalized to the amount of $18 \mathrm{~S}$ rRNA present in each lane. This was determined by hybridizing stripped filters to an oligo spanning nucleotides 151-180 of rat 18S rRNA (Chan et al., 1984) that had been end-labeled with $\left[\gamma^{32} \mathrm{P}\right]$ ATP $(>3000 \mathrm{Ci} / \mathrm{mmol}$, Amersham, Arlington Heights, IL) and polynucleotide kinase, followed by PhosphorImager analysis.

For RNase protection analysis, we synthesized antisense RNA probes from the p21-8 clone of rat retina CPE as described previously (Nickells et al., 1993), except that these transcripts were synthesized by incorporating $\left[\alpha-{ }^{32} \mathrm{P}\right]$ uridine triphosphate (UTP; $>3000 \mathrm{Ci} / \mathrm{mmol}$, Amersham). This probe protects a 147 nucleotide fragment of CPE, which includes a stretch of the poly(A) tail. After gel purification, $\sim 5 \times 10^{5} \mathrm{dpm}$ of RNA probe was precipitated with $2 \mu \mathrm{g}$ of total RNA from individual time points. For controls, RNA probe was precipitated with an equal mass of yeast tRNA. RNA pellets were air-dried and then resuspended in $20 \mu \mathrm{l}$ of hybridization buffer $(80 \%$ formamide, $40 \mathrm{~mm}$ PIPES, $\mathrm{pH} 6.8,1 \mathrm{~mm}$ EDTA, $200 \mathrm{~mm}$ sodium acetate) and heated to $95^{\circ} \mathrm{C}$ for $5 \mathrm{~min}$ in a 9600 Thermocycler (Perkin-Elmer, Norwalk, CT) followed by rapid cooling to $50^{\circ} \mathrm{C}$. The samples were incubated at this temperature for $16-18 \mathrm{hr}$. After hybridization, unbound probe in each sample was digested with $10 \mathrm{U}$ of RNase ONE (Promega, Madison, WI) for $1 \mathrm{hr}$ at room temperature. Protected RNA probe was then precipitated and analyzed by denaturing polyacrylamide gel electrophoresis and autoradiography followed by PhosphorImager analysis. To normalize the levels of protected probe for each sample, equal aliquots of RNA were also analyzed by Northern blotting to quantify the amount of $18 \mathrm{~S}$ rRNA in each sample as described above.

CPE antisera, indirect immunofluorescence, and Western blot analysis. Polyclonal antisera against CPE were a gift from Dr. Lloyd Fricker (Yeshiva University, New York, NY). Western blotting was carried out as described by Azarian et al. (1993). CPE antisera was used at a 1:1000 dilution. A monoclonal antibody against $\beta$-actin (Sigma, St. Louis, MO) was used as an internal control to monitor protein loading in these experiments. CPE protein levels were quantified by scanning Western blot membranes on a Hewlett Packard ScanJet IIcx followed by densitometer analysis using National Institutes of Health Image (version 1.57).

Immunofluorescent staining was carried out as described by Azarian et al. (1993) with the following modifications. Whole globes stored in secondary fix were equilibrated in $30 \%$ sucrose and embedded in Histo Prep (Fisher Scientific, Pittsburgh, PA). Thick cryosections (5-6 $\mu \mathrm{m})$ of the entire globe were cut and used for immunolabeling. Sections were incubated overnight at $4^{\circ} \mathrm{C}$ in $100 \mathrm{~mm}$ phosphate buffer, $\mathrm{pH} 7.2$, containing a 1:50 dilution of antisera. After washing to remove the primary antibodies, the sections were incubated further with a goat anti-rabbit secondary IgG conjugated to Texas Red (Jackson ImmunoResearch, West Grove, PA). Indirect immunofluorescence was monitored using a Zeiss Axiophot microscope (Thornwood, NY). To control for nonspecific binding, the CPE antibodies were preincubated with their respective peptides (a gift from Dr. Fricker) at a 2:1 ratio of peptide to antisera for $2 \mathrm{hr}$ at room temperature before applying them to sectioned material.

In situ hybridization. In situ hybridization was carried out using the Xenopus whole-mount procedure described by Harland (1991) as modified by $\mathrm{Li}$ et al. (1994). Basically, globes stored in secondary fix were washed in sterile $0.9 \%$ saline solution. Small blocks of retina, $\sim 1-2 \mathrm{~mm}^{2}$, were dissected from the remaining eye structures and incubated overnight in $90 \%$ methanol at $-20^{\circ} \mathrm{C}$. Each block was then protease-treated and acetylated as described by $\mathrm{Li}$ et al. (1994). Antisense RNA probe synthesis was carried out using the p21-8 cDNA clone and digoxigenin-labeled UTP as described in the Genius RNA-labeling protocol available from Boehringer Mannheim (Indianapolis, IN). After a prehybridization incubation in hybridization buffer $(50 \%$ formamide, $5 \times \mathrm{SSC}, 1 \mathrm{mg} / \mathrm{ml}$ yeast RNA, $1 \times$ Denhardt's solution, $0.1 \%$ Tween-20, and $0.1 \%$ CHAPS) for 3 hr at $60^{\circ} \mathrm{C}$, blocks of retinal tissue from select time points were hybridized in the same buffer containing $200 \mathrm{ng} / \mathrm{ml}$ antisense RNA probe for 16-18 $\mathrm{hr}$ at $60^{\circ} \mathrm{C}$. After hybridization, the retina samples were washed and treated with RNase A as described by Li et al. (1994) and incubated with anti-digoxigenin antibodies conjugated to alkaline phosphatase. Hybridized RNA probe was localized by alkaline phosphatase staining overnight at $27^{\circ} \mathrm{C}$ in the dark. After staining, the samples were washed, post-fixed, and dehydrated in a methanol series to $90 \%$ to enhance the color of the alkaline phosphatase reaction product. Stained blocks of retina were then rehydrated, embedded in JB4 Plus, and cut into $5 \mu \mathrm{m}$ sections.

Computer image analysis. All figures represented here are digitized images of the original data. Gels represented as either autoradiographs or membranes from Western blots were digitized using a Hewlett Packard ScanJet IIcx flatbed scanner. In situ hybridization and indirect immunofluorescent results were originally documented as $35 \mathrm{~mm}$ color slides. These images were then digitized using a Nikon Coolscan. All images were scanned at a resolution of $300 \mathrm{dpi}$ and processed in Adobe Photoshop (version 2.5.1) using a Power Macintosh 7100. No enhancements were made to any images other than to convert color micrographs to black and white.

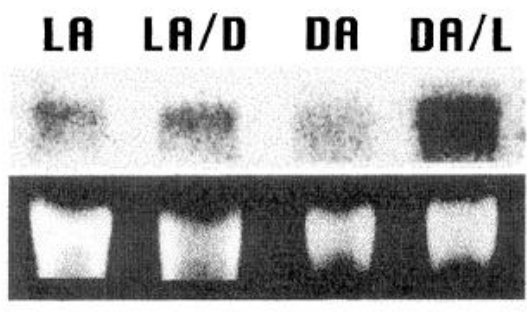

Figure 1. Northern blot analysis of retinal CPE mRNA accumulation at four time points during the light/dark cycle. Rats were entrained to a $12 \mathrm{hr}$ light/dark cycle in which the lights were turned on at 8:00 A.M. and turned off at 8:00 P.M. Total retinal RNA was isolated from rats killed after $4 \mathrm{hr}$ exposure to light (light-adapted, $L A, 12: 00$ P.M.), after $1 \mathrm{hr}$ exposure to the dark ( $L A / D, 9: 00$ P.M.), after $4 \mathrm{hr}$ exposure to the dark (dark-adapted, $D A, 12: 00$ A.M.), or after $1 \mathrm{hr}$ exposure to the light ( $D A / L, 9: 00$ A.M.). The top panel is an autoradiograph of a Northern blot showing the amount of $2.1 \mathrm{~kb}$ mRNA of CPE detected at each time point. The bottom panel shows the corresponding ethidium bromide-stained $18 \mathrm{~S}$ rRNA band of the same gel. 
Table 1. Relative changes in CPE mRNA levels for two sibling groups of rats at different time points of the light/dark cycle

\begin{tabular}{llll} 
& Experiment 1 & Experiment 2 & Average \\
\hline Light-adapted (12:00 P.M.) & $100 \%$ & $100 \%$ & $100 \%$ \\
1 hr darkness (9:00 P.M.) & $151 \%$ & $146 \%$ & $148 \%$ \\
Dark-adapted (12:00 A.M.) & $110 \%$ & $129 \%$ & $120 \%$ \\
1 hr light (9:00 A.M.) & $188 \%$ & $381 \%$ & $285 \%$
\end{tabular}

The relative mRNA levels are shown as a percentage of the level of CPE mRNA measured in light-adapted retinae in each sibling group (which is arbitrarily assigned the value of $100 \%$ ). All values shown have been normalized to the amount of $18 \mathrm{~S}$ rRNA in each sample to correct for differences in loading.

\section{RESULTS}

\section{CPE mRNA and protein levels in the rat retina fluctuate during the light/dark cycle}

Total retinal CPE mRNA and protein levels changed dramatically during the light/dark cycle of entrained Long-Evans rats. These changes were most consistently observed in rats from the same sibling groups, suggesting that the overall levels of CPE in the retina are influenced by the genetic backgrounds of these outbred animals. Thus, all experiments reported here are comparing rats from the same sibling groups.

In the first series of experiments, rats were killed at four select time points during their normal light/dark cycle. These time points were as follows: after $4 \mathrm{hr}$ of light (light-adapted), $1 \mathrm{hr}$ after dark onset, after $4 \mathrm{hr}$ of darkness (dark-adapted), and $1 \mathrm{hr}$ after light-onset. Total retinal CPE levels were quantified by Northern blotting and PhosphorImager analysis as described in Materials and Methods. Figure 1 shows a representative Northern blot of CPE levels at the four time points. There were increased amounts of detectable CPE mRNA in animals just after exposure to light or exposure to dark. Quantification of the mRNA levels at all lighting conditions for two different sibling groups is shown in Table 1. In all experiments, the message for CPE was lowest in the light-adapted retina samples. Because of this, the level of CPE mRNA was arbitrarily assigned a value of $100 \%$ in these lightadapted samples for comparative purposes. In each sibling group, CPE mRNA levels increased between 151 and $146 \%$ of the light-adapted levels within $1 \mathrm{hr}$ after the animals were exposed to darkness. After dark adaptation, these levels dropped to values slightly higher than those of light-adapted animals. Within $1 \mathrm{hr}$ after exposure to light, total retinal CPE mRNA levels increased

Figure 2. Quantification of CPE mRNA levels during the transition period from dark to light. $A$, RNase protection analysis of CPE mRNA. CPE mRNA levels increased during the first hour after exposure to light and then decreased after prolonged exposure. The time points analyzed were: just before light onset (8:00 A.M., lane 1), $30 \mathrm{~min}$ after light exposure (8:30 A.M., lane 2), 45 min after light exposure (8:45 A.M., lane 3), $60 \mathrm{~min}$ after light exposure (9:00 A.M., lane 4), and $4 \mathrm{hr}$ after light exposure (12:00 P.M., lane 5). To control for nonspecific protection of the RNA probe, an equal mass of yeast tRNA was hybridized and digested in the same experiment (lane 6). CPE mRNA protected a 147 nucleotide ( $n t)$ fragment of the original 210 nucleotide RNA probe (shown in lane 7). RNA input was standardized by measuring the amount of $18 \mathrm{~S}$ rRNA in each sample as analyzed by denaturing gel electrophoresis of duplicate aliquots $(B)$ followed by hybridization and quantification as described in Materials and Methods. $C$, Quantitative data showing the change in relative levels of CPE mRNA during the transition from dark to light for three separate sibling groups of rats. The level of CPE accumulation was determined by either RNase protection (Expt. 1, Expt. 3) or Northern blotting (Expt. 2) and normalized to the amount of 18S rRNA in each sample.
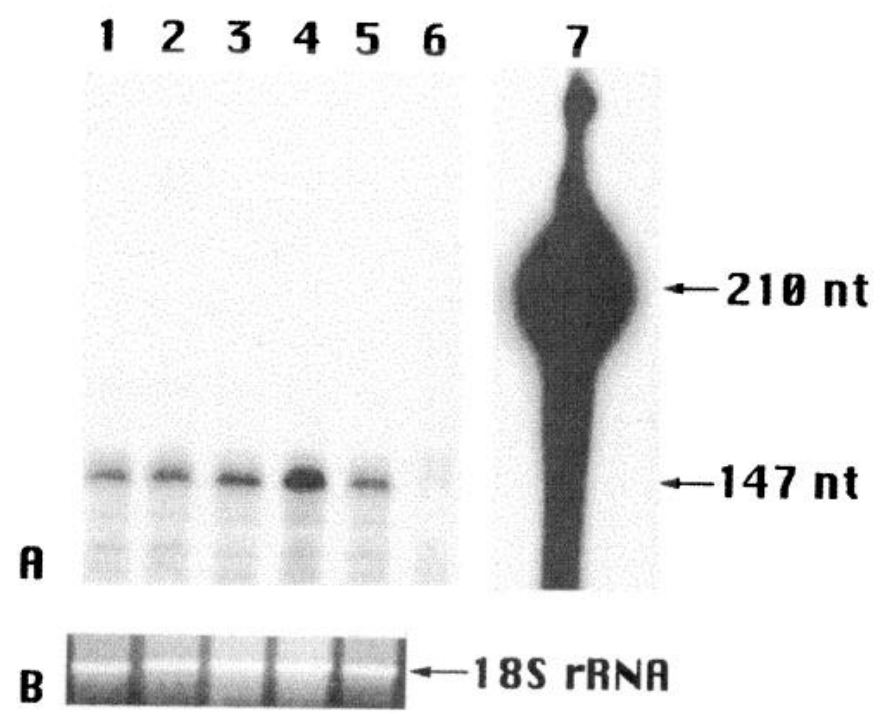

C
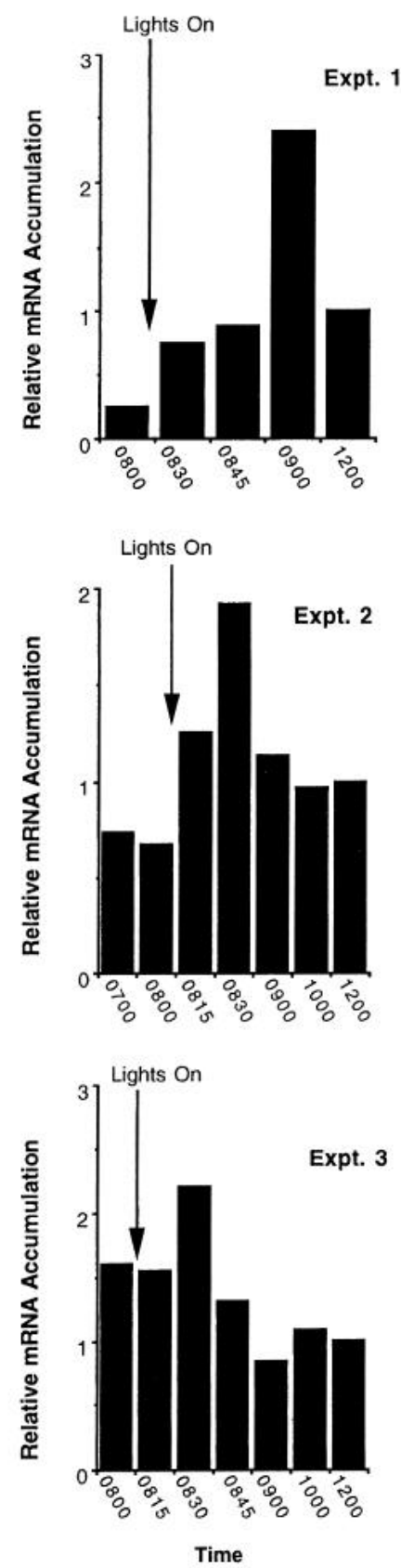
again to between 188 and $381 \%$ of the levels measured in completely light-adapted retinae.

CPE mRNA was not only most abundant in the retinal sample taken at $1 \mathrm{hr}$ after exposure to light, it also displayed the greatest detectable change in quantity compared with the samples taken at both the preceding and following time points. Because this large, transient increase in CPE mRNA levels may reflect a significant physiological requirement for increased CPE enzyme activity, the dark-to-light transition period was analyzed more closely. Figure 2 shows the changes in CPE mRNA levels during this period measured by either Northern blotting or RNase protection analysis for three different sibling groups of rats. In all three experiments, CPE mRNA levels peaked within $30 \mathrm{~min}$ to $1 \mathrm{hr}$ after light-onset, then dropped to levels similar to those of the rats killed in the dark.

We also determined whether CPE protein levels followed a similar pattern of accumulation. Two antisera were used in this study. The first was generated against an $\mathrm{N}$-terminal peptide of mature CPE (Fricker et al., 1990) and recognizes both membranebound and soluble forms of CPE. The second antiserum is directed against a $\mathrm{C}$-terminal peptide of $\mathrm{CPE}$ that is cleaved off the larger membrane-bound form of this enzyme. Consequently, this antiserum only reacts to the membrane bound CPE. In Western blot experiments, we detected two polypeptides of 58 and $55 \mathrm{kDa}$ that correspond to the major glycosylated forms of membranebound CPE (Fricker et al., 1990) using both antisera (data not shown), suggesting that the retina contains predominantly the membrane-bound form of CPE. The results of Western blot analyses on two sibling groups of rats are shown in Figure 3. In contrast to the CPE mRNA levels, CPE protein levels decreased during the dark-to-light transition, but increased again as the animals became light-adapted. The decrease in CPE protein also began just before light onset, suggesting that this phenomenon is regulated, in part, by the circadian rhythm of these entrained animals and not just by light exposure. In comparison, actin levels in the same samples remained unchanged over this period.

\section{Localization of CPE in the retina depends on the light/dark cycle}

With other light-regulated genes in the retina, an increase in mRNA is followed by a subsequent increase in protein after an appropriate lag time to allow for recruitment of message onto polysomes (Korenbrot and Fernald, 1989; Craft et al., 1990). This is also true for CPE in that protein levels increase approximately $30 \mathrm{~min}$ after detectable increases in CPE mRNA. A concomitant change in mRNA does not account for the observed decrease in CPE protein just before light onset, however. One possible explanation for the discrepancy between total retinal CPE mRNA and protein levels is that CPE is expressed in different cell-types in response to the light and the dark. To test this hypothesis, we conducted localization studies on both CPE mRNA and protein in rat retinae at different times in the light/dark cycle. Figure 4 shows a series of in situ hybridizations carried out using a digoxigeninlabeled antisense RNA probe of rat CPE. Sense RNA probes from this same clone do not hybridize above background in this tissue (Nickells et al., 1993). In dark-adapted retinae, the majority of CPE mRNA was detected in the photoreceptor cell inner segments. Within $5 \mathrm{~min}$ of light exposure, however, CPE mRNA had accumulated to detectable levels in retinal ganglion cells. An identical pattern of localization was observed in retinae after 30 min of exposure to light (data not shown). At $4 \mathrm{hr}$ of light exposure, CPE mRNA levels were greatly reduced in photorecep-

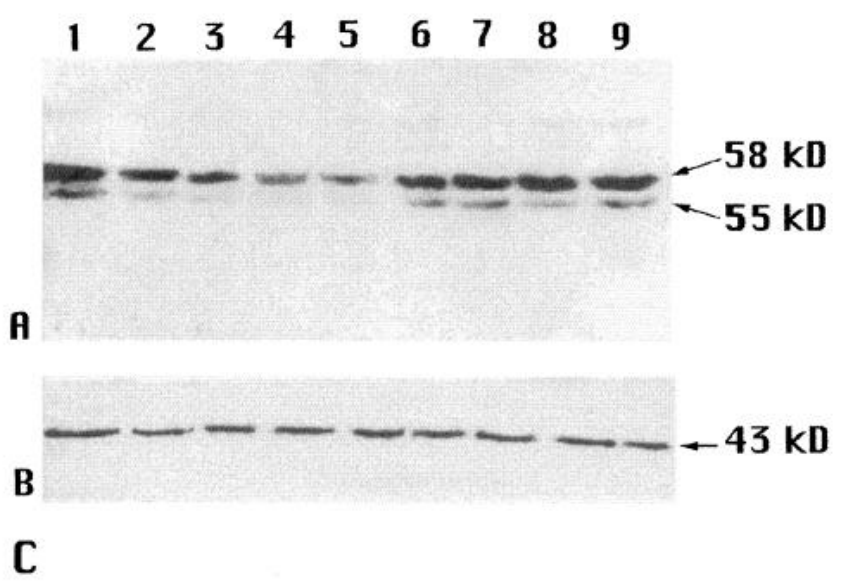

Expt. 1
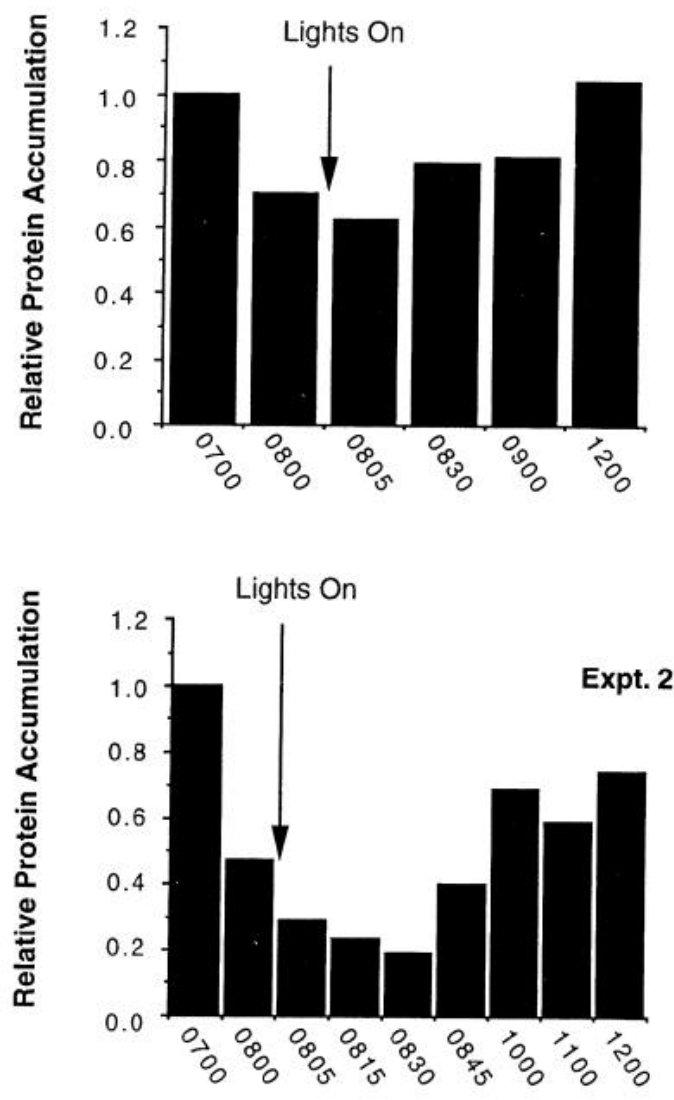

Time

Figure 3. Quantification of CPE protein levels during the transition period from dark to light. $A$, Western blot of total retinal protein $(50 \mu \mathrm{g} /$ lane $)$ challenged with a mixture of $\mathrm{N}$ - and $\mathrm{C}$-terminal antisera against CPE. These antibodies recognized two major CPE polypeptides in rat retina, measuring 58 and $55 \mathrm{kDa}$, respectively. The levels of both of these polypeptides decreased during the change from dark to light. The time points analyzed were as follows: $1 \mathrm{hr}$ before light exposure (7:00 A.M., lane 1), just before light onset (8:00 A.M., lane 2), 5 min after light exposure (8:05 A.M., lane 3), 15 min after light exposure (8:15 A.M., lane 4$), 30 \mathrm{~min}$ after light exposure (8:30 A.M., lane 5), $45 \mathrm{~min}$ after light exposure (8:45 A.M., lane 6), $2 \mathrm{hr}$ after light exposure (10:00 A.M., lane 7), $3 \mathrm{hr}$ after light exposure (11:00 A.M., lane 8), and $4 \mathrm{hr}$ after light exposure (12:00 P.M., lane 9). B, Western blot of a replicate of the gel shown in $A$ probed with a $\beta$-actin antibody. There were no detectable changes in the levels of actin during this time period. $C$, Quantification of CPE protein levels in two separate sibling groups during the change from dark to light. The levels of both the 58 and the $55 \mathrm{kDa}$ polypeptides were combined to produce the values shown. 

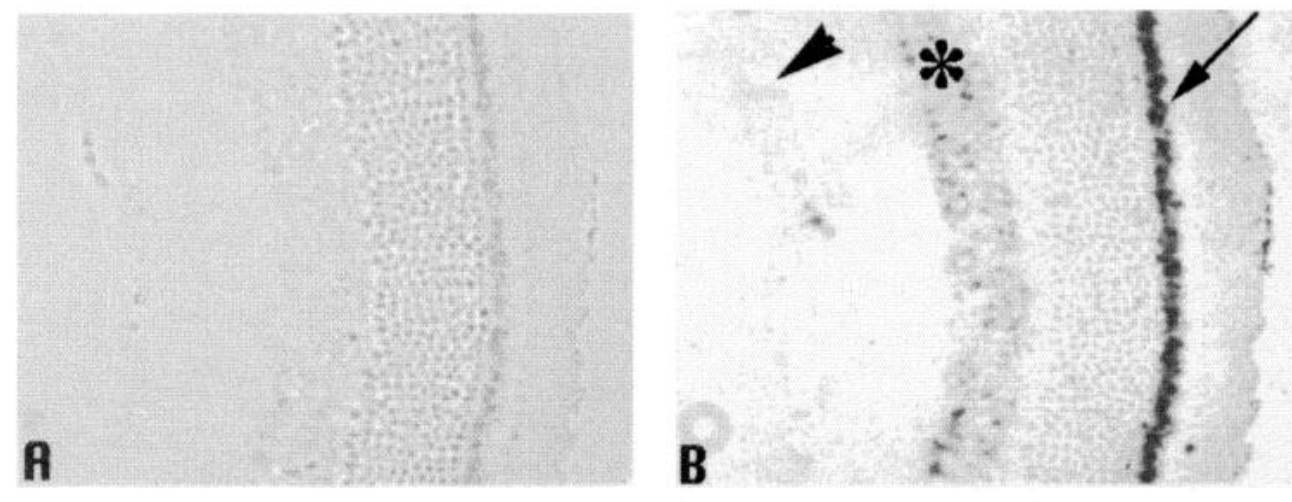

Figure 4. In situ hybridization showing the localization of CPE mRNA in the retina under different lighting conditions. $A$, $C, E, G$, Phase-contrast images of $5 \mu \mathrm{m}$ sections of rat retina hybridized with an antisense CPE RNA probe after various light/dark conditions. $B, D, F, H$, The corresponding bright-field images enhance the visualization of the dark alkaline phosphatase reaction product indicating the presence of CPE mRNA. The spatial pattern of CPE mRNA accumulation changed after exposure to light or dark. $A$ and $B$ show the localization of CPE mRNA in rat retinae after $12 \mathrm{hr}$ dark exposure. CPE mRNA was predominantly localized to the photoreceptor cells in dark-adapted retinae. After $5 \mathrm{~min}$ of light exposure $(C, D)$, CPE mRNA began to accumulate in the ganglion cells. This specimen was still attached to the pigmented epithelium and choroid, which appears as a stained area adjacent to the photoreceptor layer. This staining is caused by melanin pigment granules in these cells. CPE mRNA was also localized in the retina of rats exposed to $4 \mathrm{hr}$ of light $(E, F)$ and to $4 \mathrm{hr}$ of light and then $15 \mathrm{~min}$ of darkness $(G, H)$. Label intensity decreased in photoreceptors after prolonged (4 hr) exposure to light $(E, F)$. Labeling again increased in photoreceptor cells and decreased in ganglion cells after exposure to the dark $(G, H)$. In each micrograph, the inner segment of the photoreceptor cell layer is labeled by an arrow. The inner nuclear layer is labeled with an asterisk, and the ganglion cell layer is labeled with an arrowhead. Scale bar, $20 \mu \mathrm{m}$.
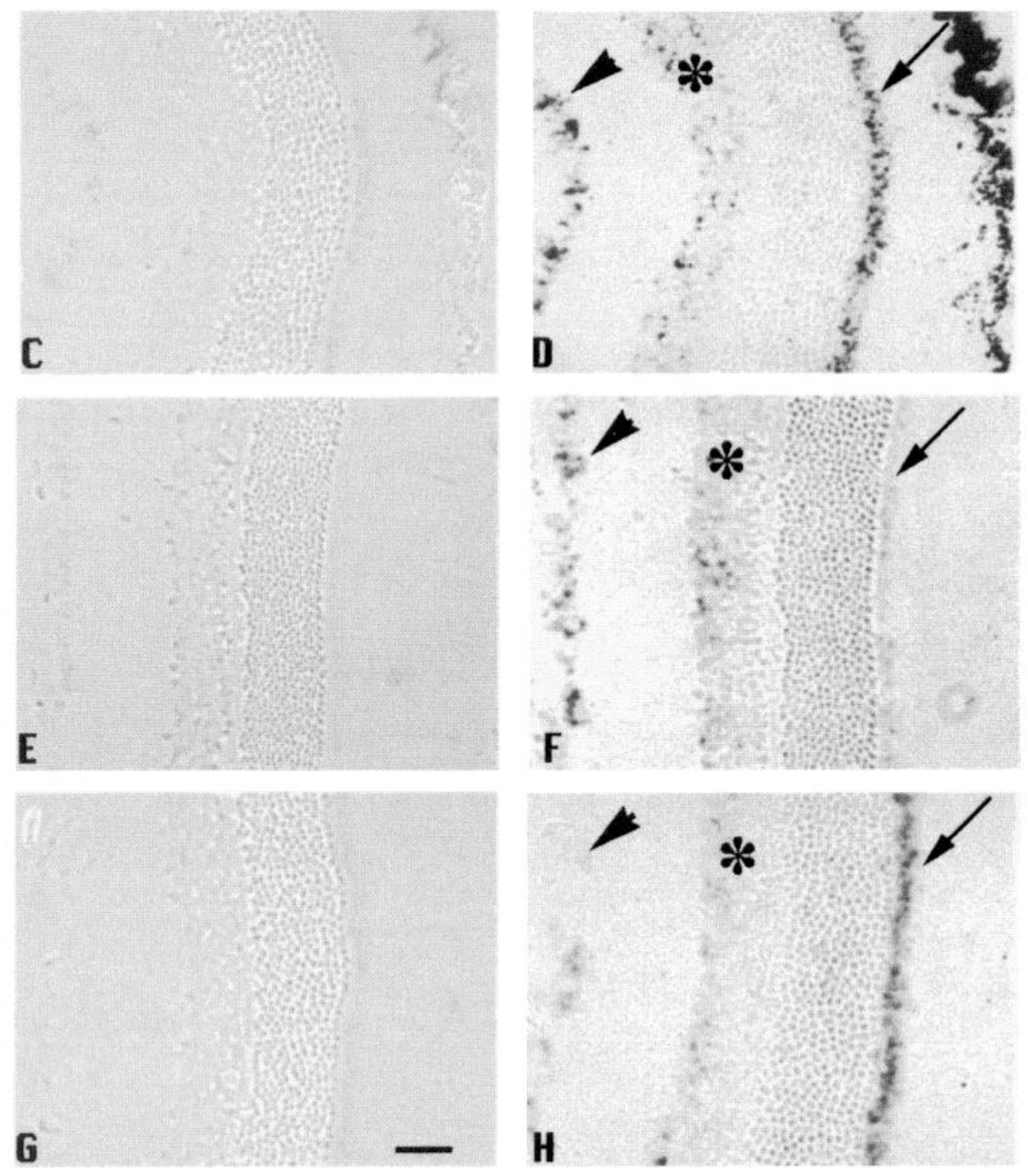

tors, but continued to be detected in ganglion cells. CPE mRNA again began to accumulate in photoreceptors within $15 \mathrm{~min}$ after the animals were reintroduced into the dark. Although CPE mRNA levels change in photoreceptors and ganglion cells, low levels of CPE mRNA were always detected in a subset of cells of the inner nuclear layer regardless of the light conditions. These cells appeared to be primarily localized in the region adjacent to the inner plexiform layer, and may represent amacrine cells.

We also determined if alterations in the light conditions re- sulted in similar changes in the localization pattern of CPE protein. Figure 5 shows the indirect immunofluorescent labeling pattern of CPE in sections of retinae exposed to the same lighting conditions shown in Figure 4. Surprisingly, CPE was localized not only to the inner segments of photoreceptor cells in dark-adapted retinae, but also to the outer segments. CPE protein was also detected in the inner nuclear layer, but little immunoreactivity was detected in the ganglion cells and the inner plexiform layer. This pattern of immunoreactive staining was essentially the same after 

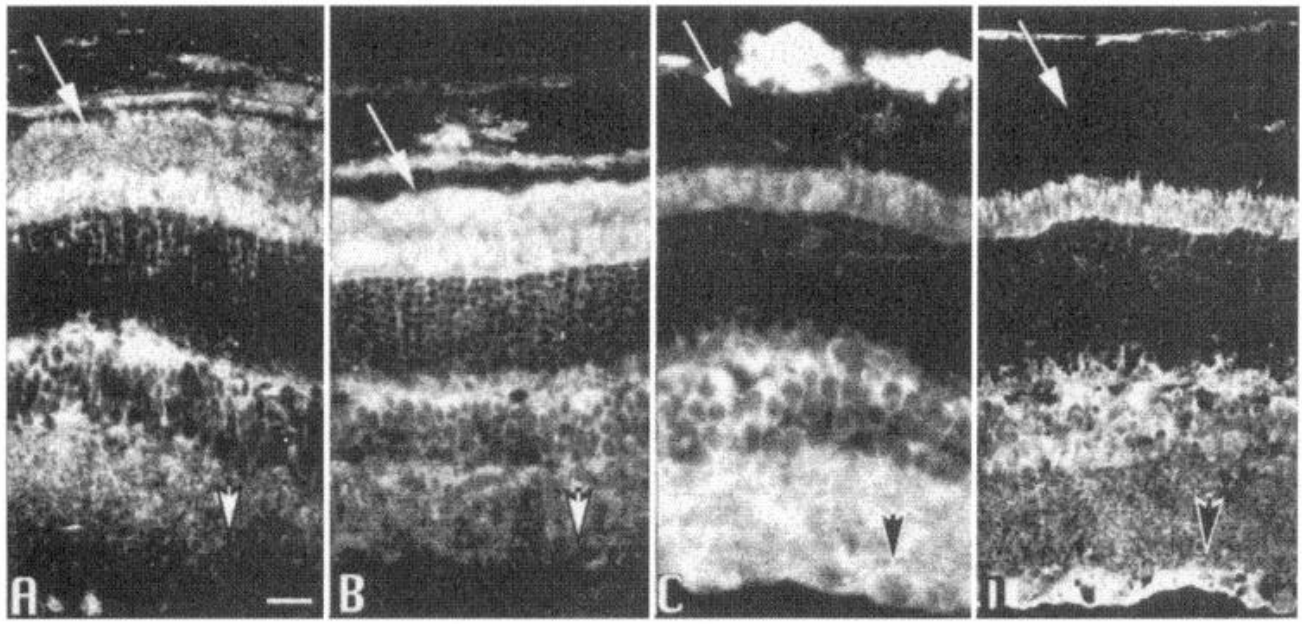

Figure 5. Indirect immunofluorescent localization of CPE protein in the retina under different lighting conditions. Cryosections $(5 \mu \mathrm{m})$ of rat retinae taken after various light/dark conditions were challenged with a CPE antiserum directed against the $\mathrm{N}$ terminus of the protein. The localization of CPE is shown in retinae taken from rats exposed to $12 \mathrm{hr}$ of dark $(A), 12 \mathrm{hr}$ of dark followed by only $5 \mathrm{~min}$ of light $(B), 4 \mathrm{hr}$ of light $(C)$, and $4 \mathrm{hr}$ of light followed by $15 \mathrm{~min}$ of dark (D). CPE is localized to photoreceptor outer segments (arrows) in dark-adapted specimens $(A)$ and in retinae exposed to short periods of light $(B)$. Conversely, CPE immunoreactivity in the ganglion cell layer (arrowheads) was more prevalent in retinae exposed to longer durations of light $(C, D)$. Scale bar, $20 \mu \mathrm{m}$.

a $5 \mathrm{~min}$ exposure to light. After $4 \mathrm{hr}$ light exposure, however, CPE-immunoreactive staining was no longer detected in the photoreceptor outer segments, although low levels of staining were still detected in the inner segments of these cells. Instead, the majority of CPE immunoreactivity was evident in the ganglion cells and inner plexiform layer in these retinae. This pattern of immunoreactive staining was essentially unchanged in retinae after $15 \mathrm{~min}$ exposure to the dark. To test whether this staining pattern was attributable to nonspecific cross-reactivity with these antibodies, serial sections were also stained in the presence of the peptide corresponding to the epitope of CPE originally used to make the antibodies. The competing peptide reduced CPE immunoreactivity to background levels (Fig. 6).

\section{DISCUSSION}

To determine whether CPE expression in the retina is regulated by light and dark, we monitored CPE mRNA and protein accumulation in the rat retina at select points of a $12 \mathrm{hr}$ light/dark cycle. CPE mRNA levels increased during the periods of transition between dark and light, but then dropped to comparable

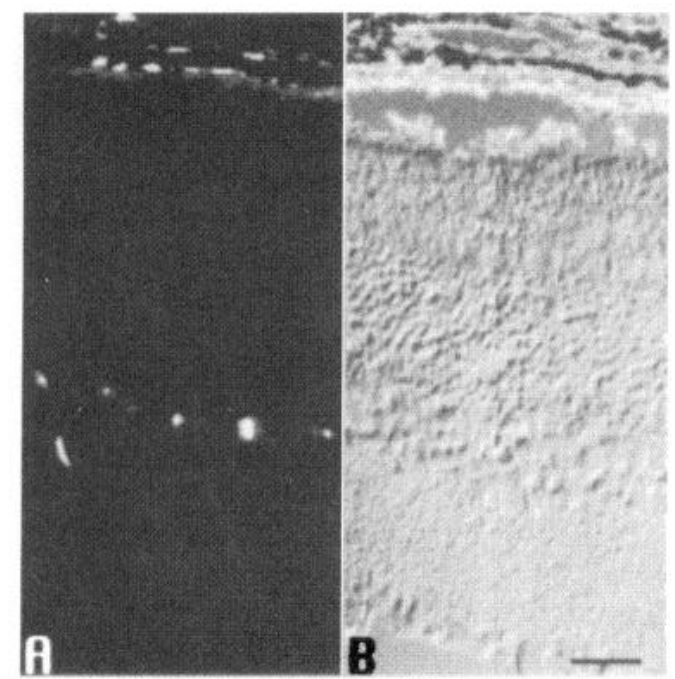

Figure 6. Indirect immunofluorescent localization of retinal CPE in the presence of competing CPE peptide. $A, B$, Fluorescent and corresponding Nomarski interference images of a section of dark-adapted retina stained with the $\mathrm{N}$-terminal antiserum previously reacted with its corresponding peptide. The peptide successfully competed off the CPE antibody from the retinal cells. Low levels of cross-immunoreactivity were still detected in the blood vessels of the retina and choroid. Scale bar, $20 \mu \mathrm{m}$. levels after prolonged exposure to each lighting condition. The transient increases in total retinal CPE mRNA may be attributable to a change in the spatial pattern of expression in CPE in response to changes in lighting conditions. In the dark, the majority of CPE mRNA was localized to photoreceptor cells. Little or no CPE was detected in retinal ganglion cells during this time. Exposure of animals to light elicited a rapid increase in CPE mRNA accumulation in ganglion cells, which was combined with a slower decrease in CPE mRNA in photoreceptors. This process was reversed when the animals were reintroduced to the dark, because CPE mRNA accumulation was restimulated in photoreceptors and reduced in ganglion cells. During all light/dark changes, however, CPE expression remained relatively constant in a subset of cells of the inner nuclear layer. The additive measurement of CPE mRNA in both ganglion cells and photoreceptors likely accounts for the transient increases in total retinal CPE detected on Northern blots and RNase protection assays during the light/dark transition periods.

Similar changes in the localization of CPE protein were also observed by indirect immunofluorescence, although the detectable accumulation of CPE protein in ganglion cells appeared to occur more slowly than for the mRNA. Measurements of total retinal CPE protein by Western blotting reflected this slower rate of accumulation in retinal ganglion cells, but also suggested that the rate of decay of CPE protein in photoreceptor cells was relatively high and was initiated even before exposure to light. A high rate of CPE loss in photoreceptors may be partly attributed to loss of CPE in the outer segments during the diurnal increase in disk shedding (LaVail, 1976). The high rate of CPE depletion in photoreceptors combined with a relatively slower rate of CPE synthesis in ganglion cells may account for the transient decrease in total retinal CPE protein observed during the dark-to-light transition.

\section{The role of CPE in different retinal cell types}

CPE expression is often used as an indicator of neuropeptide biosynthesis (Vilijn et al., 1989). In the retina, neuropeptides have been reported in amacrine cells in the inner nuclear layer, so it is not surprising that $\mathrm{CPE}$ is expressed in these cells. Neuropeptides have also been reported in retinal ganglion cells (for review, see Berman, 1991; Gunturkun and Karten, 1991; Shibata et al., 1992), although at lower levels. In both of these cell populations, neuropeptides likely act as neurotransmitters involved in cell-cell communication within the retina and between the retina and the brain. Because the majority of ganglion cell neurochemical activ- 
ity is stimulated by light, the light-induced expression of CPE in ganglion cells is consistent with a role in processing neurotransmitters. The apparent constitutive expression in cells in the inner nuclear layer may reflect a different mode of neuropeptide regulation in these cells. In the chick retina, neuropeptides such as enkephalin accumulate in amacrine cells during periods of relative inactivity and become depleted during periods of activity (Boelen et al., 1994). These observations are consistent with the continuous processing of neuropeptides in these cells and, therefore, a constant level of CPE.

The function of CPE in photoreceptors is not as obvious. Photoreceptors primarily use amino acids as neurotransmitters (for review, see Berman, 1991). In other neurons, CPE is present in the secretory granules containing cryptic peptides (Fricker and Snyder, 1982; Klein et al., 1992; Fricker and Devi, 1993), and processing generally continues while the vesicles are being transported to the axonal termini. Our indirect immunofluorescent studies demonstrate localization of some CPE in the outer plexiform layer of the retina, which is consistent with the processing of neurotransmitter peptides in photoreceptors. Staining in this region, however, may be contributed by other cell types in addition to photoreceptors (e.g., horizontal and bipolar neurons). In addition, CPE is also localized to photoreceptor outer segments, which would be inconsistent with a role in processing neurotransmitters. It is possible that neuropeptides processed in photoreceptors may have nontransmitter functions in the retina, acting instead as effectors of retinal homeostasis. One intriguing possibility for CPE function may be to process opioid neuropeptides (e.g., enkephalins) that affect melatonin levels in the retina (Rohde et al., 1993a,b). Melatonin levels increase during the dark in the retinae of several vertebrate species (Cahill and Besharse, 1993; Faillace et al., 1994) and melatonin itself is synthesized by photoreceptors in the amphibian retina (Cahill and Besharse, 1993). By virtue of indirectly regulating melatonin levels, CPE may be an important component in the regulation of the vertebrate circadian clock (Cahill and Besharse, 1993) and/or intraocular pressure (Rohde et al., 1993a). To date, however, there have been no reports of neuropeptide expression in photoreceptors. This lack of detection may simply be related to the "constitutive," or continuous, secretion of processed peptides similar to that observed in astrocytes (Klein et al., 1992). Under such conditions, neuropeptide concentration never reaches high enough levels to be detected by standard immunocytochemical techniques.

\section{CPE regulation and the expression of c-fos}

Light and dark stimulate changes in the patterns of gene expression in the vertebrate retina. One of the ways that these patterns can change is at the level of gene transcription, suggesting that there might also be light-inducible effectors that regulate these downstream genes. One of these effectors appears to be the product of the $c$-fos gene. Fos expression is rapidly induced by a variety of external stimuli, including light exposure. This has been best documented in the suprachiasmatic nucleus of the hypothalamus (Takeuchi et al., 1993), which is the site of the circadian pacemaker in mammals (for review, see van den Pol and Dudek, 1993). Fos expression in the retina is also induced by light (Sagar and Sharp, 1990; Smeyne et al., 1992). More recently, Nir and Agarwal (1993) described transient increases in total retinal c-fos mRNA accumulation during the transition periods between light and dark. Yoshida et al. (1993) carried out an in situ hybridization study in rats and described spatial changes in the c-fos expression pattern in the retina during the light/dark cycle. In this latter study, c-fos mRNA was detected at high levels in photoreceptors in dark-adapted retinae, but not in other cell types. This pattern changed after exposure to light, when c-fos mRNA began to accumulate in cells of both the inner nuclear and ganglion cell layers, while dropping dramatically in the photoreceptors. The pattern and kinetics of expression of c-fos in the light and dark are strikingly similar to the patterns detected for CPE, suggesting that Fos may regulate CPE expression in the retina. This would be consistent with an earlier report that Fos regulates neuropeptide. synthesis in the hippocampus after seizure (Sonnenberg et al., 1989). As an initial test to determine whether Fos could regulate CPE expression, we scanned the sequence of the rat CPE gene-regulatory region [Jung et al., 1991 (Genbank accession number L07273)] for potential Fos/Jun-binding sites using a subdirectory of AP-1 sites available in the MacVector DNA sequence analysis software (version 4.5). This search identified five potential sites (data not shown) within the region of the CPE promoter $(-12$ to -395$)$ that directs enhanced transcription of a reporter gene in transient transfection assays (Jung et al., 1992). Interestingly, one of these sites is a $6 / 8 \mathrm{bp}$ match to the AP-1 site identified in the proenkephalin gene by Sonnenberg et al. (1989). This site, termed "enk-2" in the proenkephalin gene, lies next to a second regulatory site, "enk-1," which is also present as a $6 / 8$ bp malch in the CPE promoter (data not shown). We are currently investigating whether Fos/Jun complexes can bind to these potential AP-1 sites of the CPE promoter both in vitro and in vivo. The identification of $\mathrm{CPE}$ as a downstream target for Fos/Jun regulation would be one of the first such genes identified in the retina and would contribute to our understanding of the function of Fos in this tissue.

\section{REFERENCES}

Azarian SM, Schlamp CL, Williams DS (1993) Characterization of calpain II in the retina and photoreceptor outer segments. J Cell Sci 105:787-798.

Berman ER (1991) Biochemistry of the Eye. New York: Plenum.

Boelen MK, Wellard J, Dowton M, Morgan IG (1994) Endogenous dopamine inhibits the release of enkephalin-like immunoreactivity from amacrine cells of the chicken retina in the light. Brain Res 645:240-246.

Bowes C, van Veen T, Farber DB (1988) Opsin, G-protein and $48 \mathrm{kDa}$ protein in normal and rd mouse retinas: developmental expression of mRNAs and proteins and light/dark cycling of mRNAs. Exp Eye Res 47:369-390.

Cahill GM, Besharse JC (1993) Circadian clock functions localized in Xenopus retinal photoreceptors. Neuron 10:573-577.

Chan YL, Gutell R, Noller HF, Wool IG (1984) The nucleotide sequence of a rat $18 \mathrm{~S}$ ribosomal ribonucleic acid gene and a proposal for the secondary structure of $18 \mathrm{~S}$ ribosomal ribonucleic acid. J Biol Chem 259:224-230.

Craft CM, Whitmore DH, Donoso LA (1990) Differential expression of mRNA and protein cncoding retinal and pineal S-antigen during the light/dark cycle. J Neurochem 55:1461-1473.

Eipper BA, Mains RE (1988) Peptide alpha-amidation. Annu Rev Physiol 50:333-344.

Faillace MP, Sarmiento MI, Siri LN, Rosenstein RE (1994) Diurnal variations in cyclic AMP and melatonin content of the golden hamster retina. J Neurochem 62:1995-2000.

Fricker LD (1988) Carboxypeptidase F. Annu Rev Physiol 50:309-321.

Fricker LD, Devi L (1993) Posttranslational processing of carboxypeptidase $\mathrm{E}$, a neuropeptide processing enzyme, in AtT-20 cells and bovine pituitary secretory granules. J Neurochem 61:1404 1415.

Fricker LD, Snyder SH (1982) Enkephalin convertase: purification and characterization of a specific enkephalin-synthesizing carboxypeptidase localized to atrenal chromaffin granules. Proc Natl Acad Sci USA 79:3886-3890.

Fricker LD, Das B, Angeletti RH (1990) Identification of the pHdependent membrane anchor of carboxypeptidase $\mathrm{E}$ (EC 3.4.17.10). J Biol Chem 265:2476-2482.

Gunturkun O, Karten HJ (1991) An immunocytochemical analysis of the lateral geniculate complex in the pigeon (Columba livia). J Comp Neurol 314:721-749. 
Harland RM (1991) In situ hybridization: an improved whole-mount method for Xenopus embryos. Appendix G. Methods Cell Biol 36:685-695.

Isayama T, McLaughlin PJ, Zagon IS (1991) Endogenous opioids regulate cell proliferation in the retina of the developing rat. Brain Res 544:79-85.

Jung Y-K, Kunczt CJ, Pearson RK, Dixon JE, Fricker LD (1991) Structural characterization of the rat carboxypeptidase-E gene. Mol Endocrinol 5:1257-1268.

Jung Y-K, Kunczt CJ, Pcarson RK, Frickcr LD, Dixon JE (1992) Exprcssion of the rat carboxypeptidase- $E$ gene in neuroendocrine and nonneuroendocrine cell lines. Mol Endocrinol 6:2027-2037.

Klein RS, Das B, Fricker LD (1992) Secretion of carboxypeptidase E from cultured astrocytes and from AtT-20 cells, a neuroendocrine cell line: implications for neuropeptide biosynthesis. J Neurochem 58:2011-2018.

Korenbrot JI, Fernald RD (1989) Circadian rhythm and light regulate opsin mRNA in rod photoreceptors. Nature 337:454-457.

LaVail MM (1976) Rod outer segment disk shedding in rat retina: relationship to cyclic lighting. Science 194:1071-1074.

Li HS, Yang JM, Jacobson RD, Pasko D, Sundin O (1994) Pax-6 is first expressed in a region of ectoderm anterior to the early neural plate: implications for the stepwise determination of the lens. Dev Biol 162:181-194.

McGinnis JF, Whelan JP, Donoso LA (1992) Transient, cyclic changes in mouse visual cell gene products during the light/dark cycle. J Neurosci Res 31:584-590.

Nickells RW, Schlamp CL, Newton AC, Williams DS (1993) Gene expression of the neuropeptide-processing enzyme carboxypeptidase $\mathrm{E}$ in rat photoreceptor cells. J Neurochem 61:1891-1900.

Nir I, Agarwal N (1993) Diurnal expression of $c$-fos in the mouse retina. Mol Brain Res 19:47-54.

Rodriguez C, Brayton KA, Brownstein M, Dixon JE (1989) Rat carboxypeptidase H. J Biol Chem 264:5988-5995.

Rohde BH, Li BHP, Chiou GCY (1993a) Effects of melatonin and haloperidol given via vortex vein on the intraocular pressure. Ophthalmic Res 25:10-15.
Rohde BH, Zhu M, el Messiry S, Chiou GCY (1993b) Effects of some opiates and opioid peptide eyedrops on ocular melatonin regulation in rabbits. Ophthalmic Res 25:378-385

Sagar SM, Sharp FR (1990) Light induces a Fos-like nuclear antigen in retinal neurons. Mol Brain Res 7:17-21.

Smeyne RJ, Schilling K, Rebertson L, Luk D, Oberdick J, Curran T, Morgan JI (1992) Fos-lacZ transgenic mice: mapping sites of gene induction in the central nervous system. Neuron 8:13-23.

Sonnenberg JL, Rauscher III FJ, Morgan JI, Curren T (1989) Regulation of proenkephalin by Fos and Jun. Science 246:1622-1625.

Shibata S, Tsuneyoshi A, Hamada T, Tominaga K, Watanabe S (1992) Effect of substance $\mathrm{P}$ on circadian rhythms of firing activity and the 2 -deoxyglucose uptake in the rat suprachiasmatic nucleus in vitro. Brain Res 597:257-263.

Takeuchi J, Shannon W, Aronin N, Schwartz WJ (1993) Compositional changes of AP-1 DNA-binding proteins are regulated by light in a mammalian circadian clock. Neuron 11:825-836.

van den Pol AN, Dudek FE (1993) Cellular communication in the circadian clock, the suprachiasmatic nucleus. Neuroscience 56:793-811.

Vilijn M-H, Das B, Kessler JA, Fricker LD (1989) Cultured astrocytes and neurons synthesize and secrete carboxypeptidase $E$, a neuropeptide-processing enzyme. J Neurochem 53:1487-1493.

Watt CB, Florack VJ (1991) A double-label study demonstrating that enkephalin and somatostatin are localized in separate populations of amacrine cells in the Iarval tiger salamander retina. Neurosci Lett $133: 86-88$

Watt CB, Florack VJ (1994) A triple-label analysis demonstrating that enkephalin-, somatostatin- and neurotensin-like immunoreactivities are expressed by a single population of amacrine cells in the chicken retina. Brain Res 634:310-316.

Watt CB, Florack VJ, Lam DMK (1991) A double-label analysis demonstrating that all enkephalin-immunoreactive amacrine cells in the chicken retina express neurotensin immunoreactivity. Brain Res 566:337-341.

Yoshida K, Kawamura K, Imaki J (1993) Differential expression of $c$-fos mRNA in rat retinal cells: regulation by light/dark cycle. Neuron 10: 1049-1054. 